\title{
Indications for 3-D diagnostics and navigation in dental implantology with the focus on radiation exposure: a systematic review
}

Burkhard Kunzendorf ${ }^{*}$ (D, Hendrik Naujokat and Jörg Wiltfang

\begin{abstract}
Background: Dental implants are a common restorative method used to replace missing teeth. Implant placement techniques guided by three-dimensional imaging and navigation are becoming more widely available.

Objective: The present review focused on the following questions: 1. What are the advantages and disadvantages of 2-D versus 3-D imaging in dental implantology? 2. What are the advantages and disadvantages of freehand implant placement in comparison with navigation-guided implant placement?

Methods: A systematic review was performed, based on the Preferred Reporting Items for Systematic Reviews and Meta-analysis (PRISMA) statement. The following libraries were searched for relevant literature: PubMed, Embase, Arbeitsgemeinschaft der Wissenschaftlichen Medizinischen Fachgesellschaften (AWMF) Online, and the Cochrane Library. The risk of bias was assessed using the Scottish Intercollegiate Guidelines Network (SiGN) checklist. A total of 70 studies were included after screening, and the evidence from these was gathered for review.

Results: Three-dimensional imaging is advantageous in terms of image quality, and it provides a distortionfree evaluation of the implant site. However, it is also associated with higher costs and increased radiation exposure. Dynamic and static navigation are equal in accuracy and are both more accurate compared with the freehand method. No benefit in terms of implant survival could be demonstrated within the first 5 years for any specific method.
\end{abstract}

Discussion: A panoramic X-ray with a reference body often provides sufficient imaging and is the primary method for two-dimensional imaging. Cone beam computed tomography with low-dose protocol settings should be used if three-dimensional imaging is needed. Navigational support should be considered in the event of especially complex cases.

Conclusion: The guidance technique used for implant placement should be decided on an individual basis. With the increasing availability of three-dimensional imaging, there should also be an increase in awareness of radiation exposure.

Keywords: Dental implants, Cone beam CT, Navigation, 3-D imaging, 2-D imaging

* Correspondence: Burkhard-Kunzendorf@gmx.de

Department of Oral and Maxillofacial Surgery, University Hospital of

Schleswig-Holstein, Campus Kiel, Arnold-Heller-Straße 3, 24105 Kiel, Germany

Springer Open (c) The Author(s). 2021 Open Access This article is licensed under a Creative Commons Attribution 4.0 International License, which permits use, sharing, adaptation, distribution and reproduction in any medium or format, as long as you give appropriate credit to the original author(s) and the source, provide a link to the Creative Commons licence, and indicate if changes were made. The images or other third party material in this article are included in the article's Creative Commons licence, unless indicated otherwise in a credit line to the material. If material is not included in the article's Creative Commons licence and your intended use is not permitted by statutory regulation or exceeds the permitted use, you will need to obtain permission directly from the copyright holder. To view a copy of this licence, visit http://creativecommons.org/licenses/by/4.0/. 


\section{Background}

Dental implants are a well-established method of prosthetic oral rehabilitation. High-quality imaging of the bone and surrounding anatomical structures is necessary for proper diagnosis, implant-planning, and implant placement. In many cases, two-dimensional (2-D) radiographic images are sufficient; however, if all relevant anatomical structures cannot be evaluated, or if further information is needed $[1,2]$, three-dimensional (3-D) imaging might be helpful [3].

Throughout their history, many dental implants were placed using the freehand method. Although an experienced surgeon can achieve good results with this method, the use of static or dynamic navigation is well established and seems to improve the outcome in terms of placement accuracy, while protecting vulnerable adjacent structures [4].

The present review was conducted to evaluate the advantages and disadvantages of $2-\mathrm{D}$ versus 3-D imaging techniques, as well as those of different navigation methods. This review aimed to provide a more detailed view of guidance techniques for implant placement.

\section{Materials and methods}

The present systematic review was based on the Preferred Reporting Items for Systematic Reviews and Meta-analysis (PRISMA) statement, with two focused research questions:

1. What are the advantages and disadvantages of 2-D versus 3-D imaging techniques in dental implantology?

2. What are the advantages and disadvantages of freehand implant placement in comparison with navigation-guided implant placement?

\section{Search strategies}

The systematic literature search for the present review was performed using the following databases: PubMed, Embase, Arbeitsgemeinschaft der Wissenschaftlichen Medizinischen Fachgesellschaften (AWMF) Online, and the Cochrane Library. Literature published from 2010 to September 2019 was searched for eligible articles. Endnote X9 was used as the citation software. The search criteria were based on two population, intervention, comparison, outcome (PICO) questions using the following terms:

\section{Population: dental implant}

Intervention: cone beam computed tomography (CBCT), cone beam CT, multi-slice computed tomography (MSCT), multi-slice $\mathrm{CT}$
Comparison: orthopantomogram, panoramic X-ray, pantomogram, dental panoramic radiograph

Outcome: bone quality, distance measurement, inferior alveolar nerve, incisive nerve, radiation, guideline, review, cost, outcome, resolution, accuracy

\section{Population: dental implant, endosseous implant}

Intervention: guided, navigation (static, dynamic)

Comparison: freehand

Outcome: accuracy, survival, failure, nerve, periimplantitis, pain, positioning, cleft

The search terms for the two PICO questions lead to a variety of combinations. The following list presents the search combinations as it was used for the main source (PubMed):

\section{PICO:}

1. CBCT; 2. cone beam CT; 3 . orthopantomogram; 4. panoramic X-ray; 5. pantomogram; 6. dental panoramic radiograph: 7. MSCT; 8. multi-slice CT; 9. dental implant; 10. bone quality; 11. distance measurement, 12. inferior alveolar nerve; 13 . incisive nerve; 14 . radiation; 15. guideline; 16 . review; 17 . cost; 18 . outcome; 19. resolution; 20. accuracy

\begin{tabular}{lllll}
\hline Search combinations & $\begin{array}{l}\text { Search } \\
\text { results }\end{array}$ & $\begin{array}{l}\text { Title } \\
\text { /abstract }\end{array}$ & $\begin{array}{l}\text { Full } \\
\text { text }\end{array}$ & Included \\
(3 OR 4 OR 5 OR 6) AND (1 OR 2 OR & 13 & 7 & 4 & 1 \\
7 OR 8) AND 10 & & & & \\
(3 OR 4 OR 5 OR 6) AND (1 OR 2 OR & 8 & 7 & 5 & 3 \\
7 OR 8) AND 11 & & & & \\
(3 OR 4 OR 5 OR 6) AND (1 OR 2 OR & 48 & 11 & 9 & 7 \\
7 OR 8) AND 12 OR 13 AND 9 & & & & \\
(3 OR 4 OR 5 OR 6) AND (1 OR 2 OR & 77 & 34 & 26 & 11 \\
7 OR 8) AND 14 & & & & \\
(3 OR 4 OR 5 OR 6) AND (1 OR 2 OR & 18 & 16 & 1 & 0 \\
7 OR 8) AND 17 & & & & \\
(15 OR 16) AND 1 AND 9 & 86 & 47 & 24 & 15 \\
1 AND 7 AND 19 & 29 & 13 & 10 & 7 \\
1 AND 7 AND 20 & 42 & 23 & 18 & 12 \\
(15 OR 16) AND 9 & & & & 2 \\
12 (freehand) & & & & 3 \\
\hline
\end{tabular}

2. PICO:

1. freehand; 2. guided; 3. navigation; 4. dental implant; 5. endosseous implant; 6. accuracy; 7. survival; 8. failure; 9. nerve; 10. peri-implantitis; 11. pain; 12. positioning; 13. dynamic navigation, 14. static navigation; 15 . cleft 


\begin{tabular}{lllll}
\hline Search combinations & $\begin{array}{l}\text { Search } \\
\text { results }\end{array}$ & $\begin{array}{l}\text { Title/ } \\
\text { abstract }\end{array}$ & $\begin{array}{l}\text { Full } \\
\text { text }\end{array}$ & Included \\
1 AND 2 AND 4 AND 6 & 13 & 8 & 6 & 5 \\
1 AND 2 AND 4 AND 7 & 4 & 4 & 3 & 1 \\
1 AND 2 OR 3 AND 4 OR 5 & 4 & 4 & 3 & 0 \\
AND 8 & & & & \\
1 AND 2 OR 3 AND 4 OR 5 & 1 & 1 & 1 & 0 \\
AND 9 \\
1 AND 2 OR 3 AND 4 OR 5 & 1 & 1 & 1 & 0 \\
AND 10 & & & & \\
1 AND 2 OR 3 AND 4 OR 5 & 2 & 2 & 2 & 2 \\
AND 11 & & & & \\
1 AND 2 OR 3 AND 4 OR 5 & 8 & 5 & 3 & 0 \\
AND 12 & & & & \\
1 AND 2 OR 3 AND 4 OR 5 & 0 & 0 & 0 & 0 \\
AND 15 & & & & \\
13 AND 14 AND 4 AND 5 & 14 & 11 & 5 & 3 \\
(4 OR 5) AND 1 AND 3 & 2 & 2 & 2 & 0 \\
\hline
\end{tabular}

\section{Study inclusion and exclusion criteria}

For study selection, the titles and abstracts were screened first, using the following inclusion criteria: English or German language and a clinical study. Due to the nature of comparative studies involving radiation, experimental studies were included in the search for the first PICO question. After the initial screening process, the studies were evaluated and excluded for the following reasons: studies older than 2010, case reports, and studies with less than 10 participants. The selection process is illustrated in Fig. 1.

\section{Risk of bias assessment for the selected studies}

The risk of bias and the quality of the studies were assessed using the Scottish Intercollegiate Guidelines Network (SiGN) checklist.

\section{Results}

\section{Study selection}

Overall, the research questions led to a variety of subtopics. Sufficient quality and quantity of data were available; however, due to the heterogeneity of the material, conducting a meta-analysis was not feasible. The study types varied by topic, for example, studies on radiation exposure tended to be experimental with a highly consistent setup, implant accuracy, and survival were primarily investigated in retrospective analysis and summarized in reviews, although randomized controlled trials were available.

Overall, 4 guidelines, 12 systematic reviews, 15 narrative reviews, 8 randomized controlled trials, 1 prospective cohort study, 10 retrospective analyses, and 20 experimental studies were included in the present review, emphasizing the broad availability of guidelines and systematic reviews.

\section{Risk of bias}

The risk of bias in the studies was assessed using the SiGN-checklist [5]. Overall, it appeared that there was a low risk of bias due to the high quality and the large number of studies available. The risk of bias for the included studies is listed in the attached evidence table (see Additional file 1).

\section{Indications for 3-D imaging}

In order to safely and accurately place an implant, there must be, in addition to the relevant clinical information, a sufficient radiological image of the bone and adjacent tissue and anatomic structures [6, 7]. A basic principle, when using radiation for diagnostics, is that the lowest amount of radiation should be used to obtain the required information [8]. Usually, a 2-D image with a reference body, like a panoramic X-ray, provides sufficient information $[2,9,10]$. If $2-\mathrm{D}$ imaging is not sufficient, 3-D imaging, such as CBCT is needed [11]. Occasionally, clinical information highlights the need for 3-D imaging, making 2-D imaging unnecessary. When there are questions about the soft tissue, the patient has to be referred to a specialist for computed tomography (CT) or magnetic resonance imaging (MRI).

\section{Image quality}

In general, 3-D images are superior to 2-D images in terms of image quality, as the bone can be clearly visualized distortion-free in all planes [9, 12], there are no overlay effects, and the relationship to the surrounding structures is more evident $[13,14]$. Additionally, the trabecular bone structure [15-20] and the need for augmentation can be evaluated more accurately in 3-D imaging $[2,9,14]$. Despite these advantages, in some studies, CBCT images appear to have errors that may exceed 1 $\mathrm{mm}$ in the measurements typically used for dental implants [21]. This accuracy seems to be similar with that of conventional CT [22-24]. One disadvantage of 3-D imaging compared with 2-D imaging is that the radiation exposure is usually higher with 3-D imaging [25].

\section{Radiation exposure}

The effective dose of a standard panoramic radiograph is $2.7-24.5 \mu \mathrm{Sv}$ [26-30], versus $5 \mu \mathrm{Sv}$ for a single-tooth radiograph [30]. In contrast, the effective dose of a conventional CT scan ranges from 180-2100 $\mu \mathrm{Sv}$ [31], and from 10$1000 \mu \mathrm{Sv}$ on CBCT [27, 30, 32]. The effective dose of $\mathrm{CBCT}$ for dentoalveolar imaging is $11-674 \mu \mathrm{Sv}[27,30,33$, 34 , and ranges from $11-96.2 \mu \mathrm{Sv}$ based on the scan protocols used for implant planning [35]. Such a wide range of effective doses puts an emphasis on patient- [36] and 


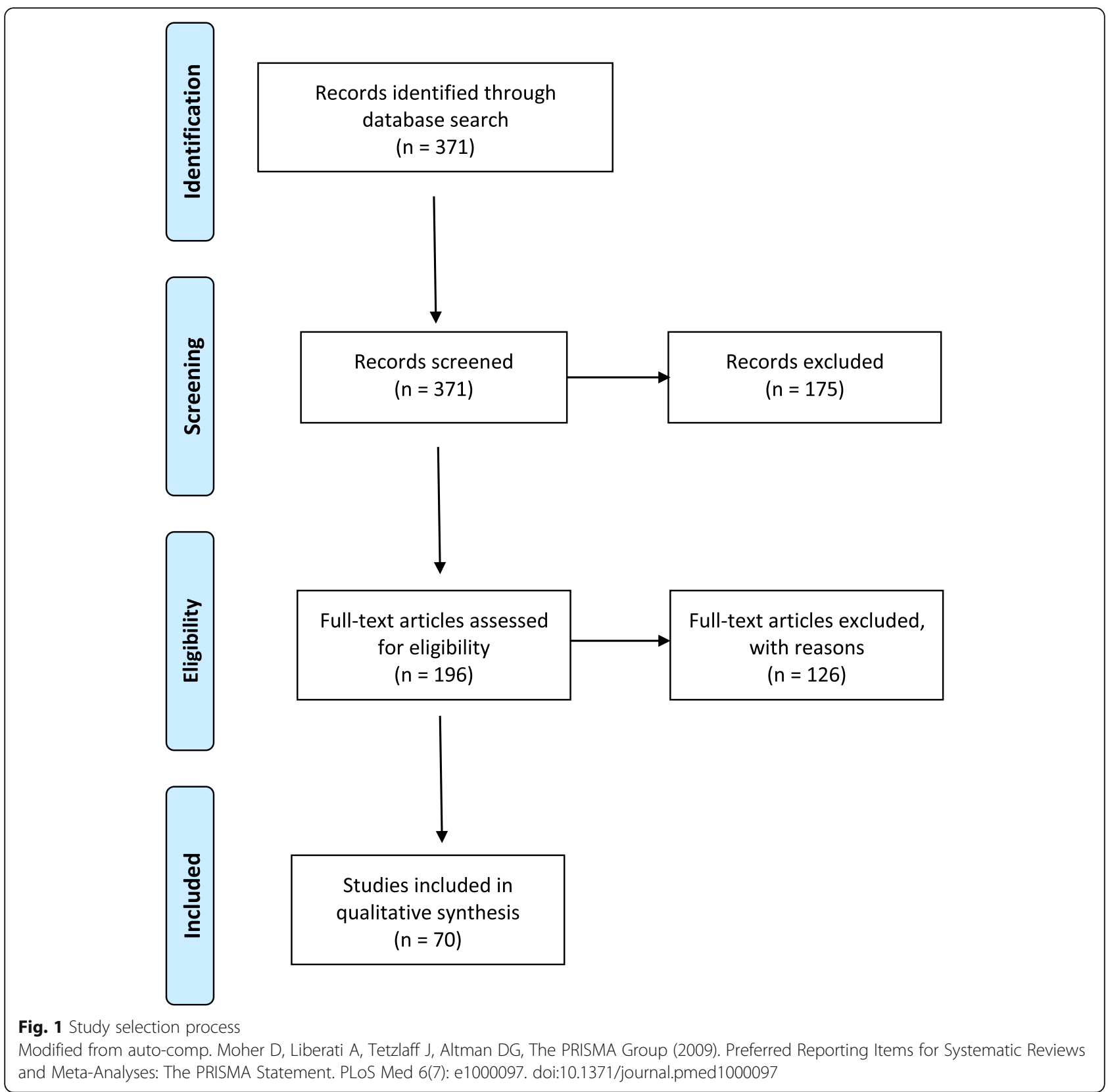

question-specific imaging protocol settings [28], such as low dose protocols $[14,35,37]$, to follow the as low as diagnostically acceptable (ALADA) principle [8, 14, 37, 38].

\section{Visibility of anatomical structures in 3-D images}

Many anatomical structures, such as the incisive nerve $[35,39,40]$, the alveolar inferior nerve [41], and its anterior loop [40, 42], are more easily visualized on CBCT images [14] in contrast to 2-D images. Since measurement inaccuracies in CBCT scans can exceed 1 $\mathrm{mm}$, a safety margin of $2 \mathrm{~mm}$ from vital structures should be utilized in implant planning [21, 37]. Although the peri-implant tissue can be visualized on CBCT images $[43,44]$, a single-tooth radiograph should be the first choice $[14,43,45,46]$.

\section{Indications for navigation for dental implantology}

Dental implant placement guided by dynamic or static navigation is more accurate than the freehand technique [4, 14, 47, 48]. In digital implant planning, 3-D imaging of the implant site is integrated into a planning software, and the implant is virtually placed. This information can then be applied to the patient by static navigation via a drilling template or by dynamic navigation with live feedback of the position of the instrument in the patient's mouth [49]. 


\section{Virtual planning}

The 3-D images uploaded into the software enable the user to identify the structure and dimensions of the imaged bone. Virtual implant databases are part of the software and have information on the length, diameter, shape, and type of implants available. Therefore, the most suitable implant, site, and orientation can be selected. This information can be exported to plan the navigation.

\section{Dynamic navigation}

For dynamic navigation, the patient has to wear a reference marker attached to a dental splint during image data acquisition. Intraoperatively, this marker serves as a reference point so that the orientation of the registered instrument can be displayed live on-screen [50]. This constant feedback enables the surgeon to place the implant with the precision that would be achieved with static navigation [51].

\section{Static navigation}

A drilling template can be created from the data output from the planning software in a variety of ways, such as 3-D printing or computer-aided manufacturing. The drilling template can provide the position, depth, and angulation of the implant. Intraoperatively, the template can be supported by different tissues, although teethand gingiva-supported templates are more accurate when compared with bone-supported templates [52]. Transgingival implantation using a drilling guide reduces postoperative pain as well as the need for analgesics, when compared with open flap surgery [53]. Many patients, especially those with preexisting conditions such as bleeding disorders, may benefit from transgingival, template-guided implant placement; however, the availability of keratinized gingiva at the implant side must be sufficient [37].

\section{Accuracy of implant placement}

When comparing freehand with static and dynamic navigation-guided implant placement, either type of navigation allows for more accurate placement than the freehand technique $[4,47,48,54-58]$. A mean difference in angular deviation of $-5.54^{\circ}$ and an apical deviation of $0.83 \mathrm{~mm}$ were calculated in a meta-analysis comparing navigation-guided vs. freehand placement [4]. Static and dynamic navigation techniques seem to be comparable in accuracy [51]. In randomized controlled trials, the deviation of the implant axis and the position of the implant tip for dynamically and statically navigated implants are as follows: $2.84 \pm$ $1.71^{\circ}$ and $1.28 \pm 0.46 \mathrm{~mm}$, and $3.06 \pm 1.37^{\circ}$ and 1.29 $\pm 0.5 \mathrm{~mm}$, respectively [37, 48,51$]$.

\section{Implant survival}

In randomized controlled trials, there was no evidence of any benefit for implants placed with navigationalguidance, particularly in terms of implant survival, periimplant bone loss, or bleeding on probing after one and three years post-implantation [59]. After 5 years, clinically insignificant marginal bone loss was detected at implants placed with navigation [53]. Postoperative swelling and bleeding, however, were reduced [37, 53, 54, 59-61] due to the minimally invasive approach provided by navigation-guided dental implant placement [60].

\section{Discussion}

The basis for safe implant placement is a good understanding of the patient's anatomy. A 2-D image, in combination with a clinical examination, is sufficient in many cases. A panoramic X-ray with a reference body should be used when possible. While 3-D images are superior in terms of image quality [13], they also have a higher radiation dose and cost. Higher accuracy can be achieved with static or dynamic navigation guidance, when compared with freehand implant placement, although more preoperative planning is necessary [14]. The radiation exposure from 3-D imaging is generally higher than that of 2-D imaging; however, there is a wide range, based on the scanning protocol $[26,32,62]$. Comparing the radiation exposure of conventional CT scans with $\mathrm{CBCT}$, conventional scans generally have higher doses, despite an overlapping range of some indications [34, 63]. For implantology, СВCT should be the first choice for 3-D imaging in most cases [14, 64]. Furthermore, radiation exposure is highly dependent on the equipment and settings utilized. A reduction in exposure can be achieved by shielding vulnerable tissues such as the thyroid gland [26], by reducing the field of view [65], the acquisition time(s), the tube voltage, or by increasing the voxel size $[8,32]$. Many CBCT scanners have programmed these settings as low-dose protocols, which are typically sufficient to provide the information required for dental implantology $[8,14,35,37,66]$.

In complex cases, 3-D images may be preferable [13, 67]. Examples of these instances are as follows: anatomical variations of the bone [68], insufficient visibility of vital structures on 2-D imaging, pathological changes visualized on 2-D imaging, pre-existing conditions, previous surgery in the maxillary sinus [14], for certain guided implantological methods [14], and for detecting possible complications after augmentation or implantation $[13,32,69]$.

To achieve high accuracy with navigational-guidance, the workflow must be well established, since inaccuracies in each individual step can compound on each other [70]. For example, the positioning of the drilling template must be secured. To ensure a safe and correct 
implant placement, a 2-mm [21] safety margin adjacent to vital structures, such as the mandibular nerve, should be utilized during the planning process [13].

The use of navigation should be considered in the following situations: for special prosthetic techniques like immediate implant placement, as support for minimally invasive techniques, or after complex jaw reconstructions [71]. There were no studies found that indicated a reduction of adverse events, such as nerve damage, when using 3-D imaging or navigationalguidance. This is most likely due to the fact that adverse events occur very infrequently, and the number requiring treatment that is needed to show a significant difference is prohibitively high for a limited study population. Additionally, it is likely that more support tools were used at difficult implant sites, which may be another reason for the absence of comparative studies. Future studies evaluating these differences would be beneficial. No studies were present investigating whether a higher accuracy in the implants placed with navigational guidance leads to a higher long-term survival of the prosthetic. Further research in this regard would also be beneficial. The limitations of the present study were primarily due to the heterogeneity of the included studies. Furthermore, many of the described outcome parameters depend on the personal skills and experience of the surgeon.

\section{Conclusion}

Although the availability of 3-D imaging is rapidly increasing, the temptation to utilize 3-D imaging in every implant placement has to be resisted. Despite the higher accuracy achieved in implants placed with the help of navigation, a difference in the survival of the implants has not been proven. In order to achieve the best possible outcome for the patient, the potential harm caused by radiation exposure also should be considered. Decisions regarding the imaging technique and the scanning protocols should be made on a case-by-case basis.

\section{Supplementary Information}

The online version contains supplementary material available at https://doi. org/10.1186/s40729-021-00328-9.

Additional file 1. Evidence table.

\section{Acknowledgements}

The present systematic review was invited to be presented at the Deutsche Gesellschaft für Implantologie (DGI) consensus conference to prepare a guideline.

\section{Authors' contributions}

Each author contributed substantially to the conception and design of the work. Additionally, each author approves the submitted version, approves to be accountable for their individual contributions, and ensures the resolution of future questions.
Funding

No funding was received for this study.

Availability of data and materials

The datasets analyzed during the present study are available at Pubmed (https://pubmed.ncbi.nlm.nih.gov/).

\section{Declarations}

Ethics approval and consent to participate

Not applicable

\section{Consent for publication}

Not applicable

\section{Competing interests}

Burkhard Kunzendorf, Hendrik Naujokat, and Jörg Wiltfang declare that they have no competing interests.

Received: 14 December 2020 Accepted: 18 March 2021

Published online: 27 May 2021

\section{References}

1. Jensen C, Raghoebar GM, Meijer HJ, Schepers R, Cune MS. Comparing two diagnostic procedures in planning dental implants to support a mandibular free-ending removable partial denture. Clin Implant Dentistry Relat Res. 2016;18(4):678-85. https://doi.org/10.1111/cid.12359.

2. Pertl L, Gashi-Cenkoglu B, Reichmann J, Jakse N, Pertl C. Preoperative assessment of the mandibular canal in implant surgery: comparison of rotational panoramic radiography $(\mathrm{OPG})$, computed tomography $(\mathrm{CT})$ and cone beam computed tomography (CBCT) for preoperative assessment in implant surgery. Eur J Oral Implantol. 2013;6(1):73-80.

3. Sahota J, Bhatia A, Gupta M, Singh V, Soni J, Soni R. Reliability of orthopantomography and cone-beam computed tomography in presurgical implant planning: a clinical study. J Contemp Dental Pract. 2017. 18(8):665-9. https://doi.org/10.5005/jp-journals-10024-2103.

4. Chen $\mathrm{S}, \mathrm{Ou} \mathrm{Q}$, Lin $\mathrm{X}$, Wang $\mathrm{Y}$. Comparison between a computer-aided surgical template and the free-hand method: a systematic review and meta-analysis. Implant Dent. 2019;28(6):578-89. https://doi.org/10.1097/ID. 0000000000000915

5. https://www.sign.ac.uk/checklists-and-notes 2020.

6. Suomalainen A, Pakbaznejad Esmaeili E, Robinson S. Dentomaxillofacial imaging with panoramic views and cone beam CT. Insights Into Imaging. 2015;6(1):1-16. https://doi.org/10.1007/s13244-014-0379-4.

7. Benavides E, Rios HF, Ganz SD, An CH, Resnik R, Reardon GT, et al. Use of cone beam computed tomography in implant dentistry: the International Congress of Oral Implantologists consensus report. Implant Dent. 2012;21(2): 78-86. https://doi.org/10.1097/ID.0b013e31824885b5.

8. Yeung AWK, Jacobs R, Bornstein MM. Novel low-dose protocols using cone beam computed tomography in dental medicine: a review focusing on indications, limitations, and future possibilities. Clin Oral Investig. 2019;23(6): 2573-81. https://doi.org/10.1007/s00784-019-02907-y.

9. Shahidi S, Zamiri B, Abolvardi M, Akhlaghian M, Paknahad M. Comparison of dental panoramic radiography and $C B C T$ for measuring vertical bone height in different horizontal locations of posterior mandibular alveolar process. J Dentistry (Shiraz, Iran). 2018;19(2):83-91.

10. Shelley AM, Glenny AM, Goodwin M, Brunton P, Horner K. Conventional radiography and cross-sectional imaging when planning dental implants in the anterior edentulous mandible to support an overdenture: a systematic review. Dento Maxillo Facial Radiol. 2014;43(2):20130321. https://doi.org/1 0.1259/dmfr.20130321.

11. Harris D, Horner K, Gröndahl K, Jacobs R, Helmrot E, Benic Gl, et al. E.A.O. guidelines for the use of diagnostic imaging in implant dentistry 2011. A consensus workshop organized by the European Association for Osseointegration at the Medical University of Warsaw. Clin Oral Implants Res. 2012;23(11):1243-53. https://doi.org/10.1111/j.1600-0501.2012.02441.x.

12. Tang Z, Liu X, Chen K. Comparison of digital panoramic radiography versus cone beam computerized tomography for measuring alveolar bone. Head Face Med. 2017;13(1):2. https://doi.org/10.1186/s13005-017-0135-3.

13. Weiss R 2nd, Read-Fuller A. Cone Beam Computed tomography in oral and maxillofacial surgery: an evidence-based review. Dentistry J. 2019;7:2. 
14. Rios HF, Borgnakke WS, Benavides $E$. The use of cone-beam computed tomography in management of patients requiring dental implants: an American Academy of Periodontology best evidence review. J Periodontol. 2017;88(10):946-59. https://doi.org/10.1902/jop.2017.160548.

15. Pauwels R, Jacobs R, Singer SR, Mupparapu M. CBCT-based bone quality assessment: are Hounsfield units applicable? Dento Maxillo Facial Radiol. 2015;44(1):20140238. https://doi.org/10.1259/dmfr.20140238.

16. Ibrahim N, Parsa A, Hassan B, van der Stelt P, Aartman $1 \mathrm{H}$, Wismeijer D. Accuracy of trabecular bone microstructural measurement at planned dental implant sites using cone-beam CT datasets. Clin Implants Res. 2014; 25(8):941-5. https://doi.org/10.1111/clr.12163.

17. Ibrahim N, Parsa A, Hassan B, van der Stelt P, Wismeijer D. Diagnostic imaging of trabecular bone microstructure for oral implants: a literature review. Dento Maxillo facial Radiol. 2013;42(3):20120075. https://doi.org/1 $0.1259 / \mathrm{dmfr} .20120075$

18. Kang SR, Bok SC, Choi SC, Lee SS, Heo MS, Huh KH, et al. The relationship between dental implant stability and trabecular bone structure using conebeam computed tomography. J Periodontal Implant Sci. 2016;46(2):116-27. https://doi.org/10.5051/jpis.2016.46.2.116.

19. Nicolielo LFP, Van Dessel J, van Lenthe GH, Lambrichts I, Jacobs R. Computer-based automatic classification of trabecular bone pattern can assist radiographic bone quality assessment at dental implant site. $\mathrm{Br} J$ Radiol. 2018;91(1092):20180437. https://doi.org/10.1259/bjr.20180437.

20. Pauwels R, Sessirisombat S, Panmekiate S. Mandibular bone structure analysis using cone beam computed tomography vs primary implant stability: an ex vivo study. Int J Oral Maxillofac Implants. 2017;32(6):1257-65. https://doi.org/10.11607/jomi.6210.

21. Fokas G, Vaughn VM, Scarfe WC, Bornstein MM. Accuracy of linear measurements on CBCT images related to presurgical implant treatment planning: a systematic review. Clin Oral Implants Res. 2018;29(Suppl 16): 393-415. https://doi.org/10.1111/clr.13142.

22. Poeschl PW, Schmidt N, Guevara-Rojas G, Seemann R, Ewers R, Zipko HT, et al. Comparison of cone-beam and conventional multislice computed tomography for image-guided dental implant planning. Clin Oral Investig. 2013;17(1):317-24. https://doi.org/10.1007/s00784-012-0704-6.

23. Dings JP, Verhamme L, Merkx MA, Xi T, Meijer GJ, Maal TJ. Reliability and accuracy of cone beam computed tomography versus conventional multidetector computed tomography for image-guided craniofacial implant planning: an in vitro study. Int J Oral Maxillofac Implants. 2019;34(3):665-72. https://doi.org/10.11607/jomi.6915.

24. CKK L, EHN P, TKL L, ECM L, Chow TW. Accuracy of radiographic measurements for implant planning using cone-beam and helical computer tomography. J Investigative Clin Dentistry. 2017:8:3.

25. The 2007 Recommendations of the International Commission on Radiological Protection. ICRP publication 103. Annals ICRP. 2007:37(2-4):1332.

26. Signorelli $L$, Patcas $R$, Peltomaki T, Schatzle M. Radiation dose of cone-beam computed tomography compared to conventional radiographs in orthodontics. J Orofac Orthop. 2016;77(1):9-15.

27. Bornstein MM, Scarfe WC, Vaughn VM, Jacobs R. Cone beam computed tomography in implant dentistry: a systematic review focusing on guidelines, indications, and radiation dose risks. Int J Oral Maxillofac Implants. 2014;29(Suppl):55-77. https://doi.org/10.11607/jomi.2014suppl.g1.4.

28. Al-Okshi A, Nilsson M, Petersson A, Wiese M, Lindh C. Using GafChromic film to estimate the effective dose from dental cone beam CT and panoramic radiography. Dento Maxillo Facial Radiol. 2013;42(7):20120343. https://doi. org/10.1259/dmfr.20120343.

29. Grunheid T, Kolbeck Schieck JR, Pliska BT, Ahmad M, Larson BE. Dosimetry of a cone-beam computed tomography machine compared with a digital x-ray machine in orthodontic imaging. Am J Orthodontics Dentofacial Orthop. 2012;141(4):436-43. https://doi.org/10.1016/j.ajodo.2011.10.024.

30. Qiang W, Qiang F, Lin L. Estimation of effective dose of dental x-ray devices. Radiat Prot Dosim. 2019;183(4):417-21

31. SEDENTEXCT project. Radiation protection: cone beam $C T$ for dental and maxillofacial radiology. Evidence Based Guidelines (v20 Final). 2011.

32. Jacobs R, Salmon B, Codari M, Hassan B, Bornstein MM. Cone beam computed tomography in implant dentistry: recommendations for clinical use. BMC Oral Health. 2018;18(1):88. https://doi.org/10.1186/s12903-0180523-5.

33. Rehani MM, Gupta R, Bartling S, Sharp GC, Pauwels R, Berris T, et al. Radiological protection in cone beam computed tomography (CBCT). ICRP
Publication 129. Ann ICRP. 2015;44(1):9-127. https://doi.org/10.1177/014664 5315575485.

34. Stratis A, Zhang G, Lopez-Rendon X, Politis C, Hermans R, Jacobs R, et al. Two examples of indication specific radiation dose calculations in dental CBCT and multidetector CT scanners. Physica medica. 2017:41:71-7.

35. Feragalli B, Rampado O, Abate C, Macri M, Festa F, Stromei F, et al. Cone beam computed tomography for dental and maxillofacial imaging: technique improvement and low-dose protocols. La Radiol Medica. 2017; 122(8):581-8. https://doi.org/10.1007/s11547-017-0758-2.

36. Shin HS, Nam KC, Park H, Choi HU, Kim HY, Park CS. Effective doses from panoramic radiography and CBCT (cone beam CT) using dose area product (DAP) in dentistry. Dento maxillo Facial Radiol. 2014;43(5):20130439. https:// doi.org/10.1259/dmfr.20130439.

37. Wismeijer D, Joda T, Flugge T, Fokas G, Tahmaseb A, Bechelli D, et al. Group 5 ITI Consensus Report: Digital technologies. Clin Oral Implants Res. 2018; 29(Suppl 16):436-42. https://doi.org/10.1111/clr.13309.

38. Jaju PP, Jaju SP. Cone-beam computed tomography: Time to move from ALARA to ALADA. Imaging Sci Dentistry. 2015;45(4):263-5. https://doi.org/1 0.5624/isd.2015.45.4.263.

39. Pires CA, Bissada NF, Becker JJ, Kanawati A, Landers MA. Mandibular incisive canal: cone beam computed tomography. Clin Implant Dentistry Related Res. 2012;14(1):67-73. https://doi.org/10.1111/j.1708-8208.2009.00228.x.

40. Ferreira Barbosa DA, Barros ID, Teixeira RC, Menezes Pimenta AV, Kurita LM, Barros Silva PG, et al. Imaging aspects of the mandibular incisive canal: A PROSPERO-registered systematic review and meta-analysis of cone beam computed tomography studies. Int J Oral Maxillofac Implants. 2019;34(2): 423-33. https://doi.org/10.11607/jomi.6730.

41. Haas LF, Dutra K, Porporatti AL, Mezzomo LA, De Luca CG, Flores-Mir C, et al. Anatomical variations of mandibular canal detected by panoramic radiography and CT: a systematic review and meta-analysis. Dento Maxillo Facial Radiol. 2016;45(2):20150310. https://doi.org/10.1259/dmfr.20150310.

42. de Brito AC, Nejaim Y, de Freitas DQ, de Oliveira Santos C. Panoramic radiographs underestimate extensions of the anterior loop and mandibular incisive canal. Imaging Sci Dentistry. 2016;46(3):159-65. https://doi.org/10. 5624/isd.2016.46.3.159

43. Sheridan RA, Chiang YC, Decker AM, Sutthiboonyapan P, Chan HL, Wang $\mathrm{HL}$. The effect of implant-induced artifacts on interpreting adjacent bone structures on cone-beam computed tomography scans. Implant Dent. 2018; 27(1):10-4. https://doi.org/10.1097/ID.0000000000000684.

44. LOL B, Mukai E, Oderich E, Porporatti AL, Pacheco-Pereira C, Tortamano P, et al. Comparative analysis of imaging techniques for diagnostic accuracy of peri-implant bone defects: a meta-analysis. Oral Surgral Med Oral Pathol Oral Radiol. 2017;124(4):432-40.e5.

45. Yepes JF, Al-Sabbagh M. Use of cone-beam computed tomography in early detection of implant failure. Dental Clin North Am. 2015;59(1):41-56. https:// doi.org/10.1016/j.cden.2014.09.003.

46. Dave M, Davies J, Wilson R, Palmer R. A comparison of cone beam computed tomography and conventional periapical radiography at detecting peri-implant bone defects. Clin Oral Implants Res. 2013;24(6):6718. https://doi.org/10.1111/j.1600-0501.2012.02473.x.

47. Alevizakos V, Mitov G, Stoetzer M, von See C. A retrospective study of the accuracy of template-guided versus freehand implant placement: a nonradiologic method. Oral Surg Oral Med Oral Pathol Oral Radiol. 2019; 128(3):220.

48. Vercruyssen M, Cox C, Coucke W, Naert I, Jacobs R, Quirynen M. A randomized clinical trial comparing guided implant surgery (bone- or mucosa-supported) with mental navigation or the use of a pilot-drill template. J Clin Periodontol. 2014;41(7):717-23. https://doi.org/10.1111/ jcpe.12231.

49. Block MS, Emery RW. Static or Dynamic navigation for implant placementchoosing the method of guidance. J Oral Maxillofac Surg. 2016;74(2):269-77. https://doi.org/10.1016/j.joms.2015.09.022.

50. Stefanelli LV, DeGroot BS, Lipton DI, Mandelaris GA. Accuracy of a dynamic dental implant navigation system in a private practice. Int J Oral Maxillofac Implants. 2019;34(1):205-13. https://doi.org/10.11607/jomi.6966.

51. Kaewsiri D, Panmekiate S, Subbalekha K, Mattheos N, Pimkhaokham A. The accuracy of static vs. dynamic computer-assisted implant surgery in single tooth space: a randomized controlled trial. Clin Oral Implants Res. 2019; 30(6):505-14. https://doi.org/10.1111/clr.13435

52. Raico Gallardo YN, da Silva-Olivio IRT, Mukai E, Morimoto S, Sesma N, Cordaro L. Accuracy comparison of guided surgery for dental implants 
according to the tissue of support: a systematic review and meta-analysis. Clin Oral Implants Res. 2017;28(5):602-12. https://doi.org/10.1111/dr.12841.

53. Tallarico M, Esposito M, Xhanari E, Caneva M, Meloni SM. Computer-guided vs freehand placement of immediately loaded dental implants: 5 -year postloading results of a randomised controlled trial. Eur J Oral Implantol. 2018;11(2):203-13.

54. Gargallo-Albiol J, Barootchi S, Salomo-Coll O, Wang HL. Advantages and disadvantages of implant navigation surgery. A systematic review. Ann Anat. 2019;225:1-10. https://doi.org/10.1016/j.aanat.2019.04.005.

55. Block MS, Emery RW, Cullum DR, Sheikh A. Implant placement is more accurate using dynamic navigation. J Oral Maxillofac Surg. 2017;75(7):137786. https://doi.org/10.1016/j.joms.2017.02.026.

56. Choi W, Nguyen BC, Doan A, Girod S, Gaudilliere B, Gaudilliere D. Freehand Versus Guided Surgery: Factors Influencing Accuracy of Dental Implant Placement. Implant Dent. 2017;26(4):500-9. https://doi.org/10.1097/ID. 0000000000000620.

57. Smitkarn P, Subbalekha K, Mattheos N, Pimkhaokham A. The accuracy of single-tooth implants placed using fully digital-guided surgery and freehand implant surgery. J Clin Periodontol. 2019;46(9):949-57. https://doi.org/1 $0.1111 /$ jcpe.13160

58. Vercruyssen M, Coucke W, Naert I, Jacobs R, Teughels W, Quirynen M. Depth and lateral deviations in guided implant surgery: an RCT comparing guided surgery with mental navigation or the use of a pilot-drill template. Clin Oral Implants Res. 2015;26(11):1315-20. https://doi.org/10.1111/clr.12460.

59. Bernard L, Vercruyssen M, Duyck J, Jacobs R, Teughels W, Quirynen M. A randomized controlled clinical trial comparing guided with nonguided implant placement: a 3-year follow-up of implant-centered outcomes. J Prosthetic Dentistry. 2019;121(6):904-10. https://doi.org/10.1016/j.prosdent.2 018.09.004.

60. Pozzi A, Tallarico M, Marchetti M, Scarfo B, Esposito M. Computer-guided versus free-hand placement of immediately loaded dental implants: 1-year post-loading results of a multicentre randomised controlled trial. Eur J Oral Implantol. 2014;7(3):229-42.

61. Jane-Salas E, Rosello LX, Jane-Palli E, Mishra S, Ayuso-Montero R, LopezLopez J. Open flap versus flapless placement of dental implants. A randomized controlled pilot trial. Odontology. 2018;106(3):340-8. https://doi. org/10.1007/s10266-018-0343-8.

62. Wrzesien M, Olszewski J. Absorbed doses for patients undergoing panoramic radiography, cephalometric radiography and CBCT. Int J Occup Med Environ Health. 2017;30(5):705-13. https://doi.org/10.13075/ijomeh.1 896.00960.

63. Pauwels R. Cone beam CT for dental and maxillofacial imaging: dose matters. Radiat Prot Dosim. 2015;165(1-4):156-61. https://doi.org/10.1093/ $\mathrm{rpd} / \mathrm{ncv} 057$.

64. Mercado F, Mukaddam K, Filippi A, Bieri OP, Lambrecht TJ, Kuhl S. Fully Digitally guided implant surgery based on magnetic resonance imaging. Int J Oral Maxillofac Implants. 2019;34(2):529-34. https://doi.org/10.11607/jomi.7076.

65. Elshenawy H, Aly W, Salah N, Nasry S, Anter E, Ekram K. Influence of Small, Midi, Medium and large fields of view on accuracy of linear measurements in CBCT imaging: diagnostic accuracy study. Open Access Macedonian J Med Sci. 2019;7(6):1037-41. https://doi.org/10.3889/oamjms.2019.232.

66. Dawood A, Brown J, Sauret-Jackson V, Purkayastha S. Optimization of cone beam $C T$ exposure for pre-surgical evaluation of the implant site. Dento Maxillo Facial Radiol. 2012;41(1):70-4. https://doi.org/10.1259/dmfr/16421849.

67. Tavelli L, Borgonovo AE, Re D, Maiorana C. Sinus presurgical evaluation: a literature review and a new classification proposal. Minerva Stomatol. 2017; 66(3):115-31. https://doi.org/10.23736/S0026-4970.17.04027-4.

68. Tyndall DA, Price JB, Tetradis S, Ganz SD, Hildebolt C, Scarfe WC. Position statement of the American Academy of Oral and Maxillofacial Radiology on selection criteria for the use of radiology in dental implantology with emphasis on cone beam computed tomography. Oral Surg Oral Med Oral Pathol Oral Radiol. 2012;113(6):817-26. https://doi.org/10.1016/j.000o.2012. 03.005 .

69. Du Toit J, Gluckman H, Gamil R, Renton T. Implant injury case series and review of the literature Part 1: Inferior alveolar nerve injury. J Oral Implantol. 2015;41(4):e144-51. https://doi.org/10.1563/AAID-JOI-D-14-00022.

70. D'Haese J, Ackhurst J, Wismeijer D, De Bruyn H, Tahmaseb A. Current state of the art of computer-quided implant surgery. Periodontol. 2017:73(1):121-33.

71. Tannyhill RJ 3rd, Troulis MJ. Implant therapy in alveolar cleft sites. Oral Maxillofacial Surg Clin North Am. 2019;31(2):207-17. https://doi.org/10.1016/ j.coms.2018.12.002.

\section{Publisher's Note}

Springer Nature remains neutral with regard to jurisdictional claims in published maps and institutional affiliations.

\section{Submit your manuscript to a SpringerOpen ${ }^{\circ}$ journal and benefit from:}

- Convenient online submission

- Rigorous peer review

- Open access: articles freely available online

High visibility within the field

- Retaining the copyright to your article

Submit your next manuscript at $\boldsymbol{\nabla}$ springeropen.com 